\title{
Innovation in Latin America through the lens of bibliometrics: crammed and fading away
}

\author{
Julián David Cortés-Sánchez ${ }^{1}$ (iD
}

Received: 2 February 2019 / Published online: 31 August 2019

(c) The Author(s) 2019

\begin{abstract}
Research in the field of innovation in business, management, and accounting (BMA) in Latin America (LATAM) has surpassed all expectations of its net output. Yet this digital tide suggests several concerns regarding its impact and both its established and emergent research topics at the individual, institutional, and country level. In this paper, an outlook of the field was developed based on a sample of +1300 documents indexed in Scopus from 1983 to 2018. Public institutions in Brazil and Colombia have been both the most cited and productive in the region. Nevertheless, documents lead by non-LATAM authors showed significant differences in both paper citations and journals' $h$-index compared to leading authors from LATAM. Three of the major concerns raised were, first, a growing interregional gap among LATAM countries. Second, the intensive use of a journal with predatory features over the last 5 years, therefore cites/document measure is at the lowest point of the past 17 years. And third, the delay of recently emergent topics in the region that have been in the literature for more than a decade, while frontier topics for BMA innovation such as those of Industry 4.0 remain unnoticed.
\end{abstract}

Keywords Innovation · Business, management and accounting · Latin America · Bibliometrics

JEL Classification $\mathrm{M} 10 \cdot \mathrm{M} 40 \cdot \mathrm{O} 30 \cdot \mathrm{Z} 1$

\section{Introduction}

The intellectual production in the field of business, management and accounting (BMA) in Latin America (LATAM) during the past 20 years has been impressive (Cortés-Sánchez 2018a). Between 1996 and 2017, 22,470 documents in the subject of BMA with at least one coauthor from LATAM have been indexed in Scopus (2018). Particularly, innovationrelated research in BMA is one of several factors that identify activities related to firms' growth (Rosenbusch et al. 2011) and is now part of the global agenda for development, to be precise, Goal No. 9 of the Sustainable Development Goals: "Industry, innovation and

Julián David Cortés-Sánchez

julian.cortess@urosario.edu.co

1 School of Management, Universidad del Rosario, Bogotá, Colombia 
infrastructure." (United Nations 2018). Reframing the query to documents with innovation as a keyword in BMA in LATAM between 1996 and 2018, + 1300 documents were found to be indexed in Scopus (2018). To navigate this amount of digital content, it is pertinent to use bibliometrics appraisal to assess document production and impact by authors, institutions, and countries, and the mutual influence between disciplines and the social capital of scholars (Zupic and Čater 2015).

The study of innovation in BMA in LATAM through the lens of bibliometrics has produced several developments, such as measurement frameworks (De Carvalho et al. 2017), industry relation (Manjarrez et al. 2016) and financing (Padilla-Ospina et al. 2018). Notwithstanding, several aspects remain to be studied and assessed, such as the regional context for the absence of research on innovation in the 1980s and 1990s, the specific peerreviewed intellectual production on innovation in BMA in LATAM as far back in time as the 1980s, the particular bibliometrics features of relevant articles, books or book chapters (i.e., number of authors, citations, journal $h$-index, publishers, affiliations, languages, open access or paywall, and so forth) and research topics published. Accordingly, the research question guiding this study is: which are the bibliometric properties of the field of innovation in BMA in LATAM in terms of output and impact (citations) by countries, institutions and authors, and related topics in the last 30 years? Accordingly, the objective of this paper was to elaborate an outlook of the field of innovation in BMA in LATAM based on a sample of +1300 documents indexed in Scopus from 1983 to 2018 .

The rest of this paper is organized as follows: In the next section, the literature review is presented, followed by the methods underlying the study. Afterward, the results are both analyzed and discussed. Finally, the conclusions are outlined.

\section{Literature review}

Innovation is a multidisciplinary concept with numerous definitions (Baregheh et al. 2009). Particularly in BMA, innovation can be considered as the invention, improvement, and implementation of certain management practices, processes, structures, or techniques that are new and are intended to further organizational goals (Birkinshaw et al. 2008). That said, the studies related to both bibliometrics and scientometrics of innovation in BMA in LATAM reviewed centered around several topics, such as: measurements, cooperation, industry relations, business models, open innovation, financing, and social innovation. Also, these studies share certain methodological aspects, namely the source for bibliometric analysis.

As a measurement framework, De Carvalho et al. (2017) looked into innovativeness measures, comprising inputs (e.g., R\&D [research and development] investments and staff qualification or patents); capabilities and processes (e.g., culture, leadership or knowledge); and outputs (e.g., number of innovations and percentage of revenues from new products). Along similar lines, Lazzarotti et al. (2011) and Lopes and De Carvalho (2012) spotted diverse themes related to Schumpeterian innovation and cooperation, such as resources and R\&D (inputs); strategic alliances, performance, management, abilities and organizational skills, knowledge and learning (capabilities and processes); and technological innovation and new product development (outputs).

Regarding industry relations, Manjarrez et al. (2016) found in their bibliometrics analysis on industry relations with innovation system players (e.g., academic, scientific or technological) a worldwide development in the subject, not so in LATAM, except for in Brazil. Ceretta 
et al. (2016) centered their analysis on business models and innovation and found that the key-terms most intertwined with those mentioned were market, management, strategy, $R \& D$, and industry. De Paulo et al. (2017) conducted a comparative assessment between developed (i.e., G7) and developing countries (i.e., BRICS) and research production on Open Innovation. Among several findings, they highlighted a significant increase in the overall research output with a vast gap between groups in terms of publication output and citations: developed countries deployed a greater relevance whereas emerging countries are still in an embryonic stage. In financing on innovation, Padilla-Ospina et al. (2018) outlined five salient topics, namely: financial constraints, funding sources (internal and external), capital structure, venture capital, and financing of technology companies. When analyzing the topic of social innovation, Silveira and Zilber (2017) agreed that the term most associated with "social innovation" was "social entrepreneurship" and that the most implemented theoretical frameworks used to study social innovation were institutional theory, social entrepreneurship, and public policy.

With the above in mind, several similitudes can be underlined. First, the search criteria were centered on innovation $+(n)$, in which $n$ was an additional topic related to innovation (i.e., open, financing, business models). Second, except for Silveira and Zilber (2017), all other studies used Web of Science (WoS) as the leading system for bibliometrics analyses. And third, the average publication date ranged from 2000 to 2013.

Based on these shared properties, this study contributes to the literature on innovation in BMA from a regional comparative standpoint (i.e., LATAM) by using Scopus. This amplifies journal coverage (Scopus: 20,346 journals vs. WoS: 13,605) of both articles and journals published by countries in Ibero-America (e.g., Spain and Brazil) (Mongeon and Paul-Hus 2016), overlapping coverage ( $\approx 84 \%$ of active titles in WoS were also indexed in Scopus) (Gavel and Iselid 2008), and publication date to 1983-2018.

\section{Methods}

Descriptive statistics, correlations, ANOVA, text mining and co-authorship analysis were employed to comprehend the bibliometrics features of the intellectual production related to innovation in BMA in LATAM. Statistical analysis was conducted in SPSS and DIVE. Text mining and co-authorship analysis were processed in VOSviewer (van Eck and Waltman 2010). VOSviewer is an open-access software tool for constructing and visualizing bibliometric networks. In this study, the text mining functionality to construct and visualize co-occurrence networks of key-terms of the documents' titles and the co-authorship network visualization were used.

\section{Sample}

This study was focused on the publishing production on innovation framed into the context of BMA. According to SCImago (Table 1), this subject is made up of ten categories.

The search criteria in Scopus was limited to documents in BMA with the keyword innovation (or innovación) published as articles, conference papers, book chapters or books by at least one (co)author from Latin American. Bibliometric data were gathered on access type (e.g., open access); language; the number of authors; affiliation and country of the leading author; document title; abstract; year of publication; source title (i.e., journal, book or proceedings); journal $h$-index and quartile; and publishers' country. Scopus and SCImago were the sources for consultation. 
Table 1 Subject categories in the subject of business, management and accounting in SCImago. Source: SCImago, n.d.
Subject categories

Accounting

Business and International Management

Business, Management and Accounting

Industrial Relations

Management Information Systems

Management of Technology and Innovation

Marketing

Organizational Behavior and Human Resource Management

Strategy and Management

Tourism, Leisure and Hospitality Management

Scopus found a total of 1330 documents published from 1983 to 2018. Table 2 presents the sample summary. Nearly half of the documents were published between 2015 and 2018, in which English was the dominant language and articles were the dominant source. In 16 out of 20 LATAM countries, it was found that there was at least one (co) author in a given document. About ninety percent of the documents had at least one (co) author affiliated to an institution located in either Brazil, Colombia, Chile, or Argentina. The complete database can be consulted in the following link: http://bit.ly/2ZL8G0i or by scanning the following QR code (Fig. 1).

\section{Results analysis}

Results are displayed in four sections. "Publishing market, citations and $h$-index distribution, and authors-citations correlation" section presents the distribution of the publishing market, citations and $h$-index as well as the results of the correlation between the number of

Table 2 Summary of the sample Source: Scopus 2018

\begin{tabular}{lcc}
\hline Country & $\begin{array}{l}\text { Documents pub- } \\
\text { lished }\end{array}$ & Percentage (\%) \\
\hline Brazil & 901 & 65 \\
Colombia & 200 & 14 \\
Chile & 84 & 6 \\
Argentina & 61 & 4 \\
Peru & 30 & 2 \\
Source & & \\
Articles & 1115 & 83 \\
Conference papers & 198 & 14 \\
Book chapters & 18 & 1 \\
Books & 2 & 0,1 \\
Language & & \\
English & 963 & 72 \\
Portuguese & 249 & 18 \\
Spanish & 166 & 12 \\
French & 2 & 0,1 \\
\hline
\end{tabular}


Fig. 1 QR code to access dataset

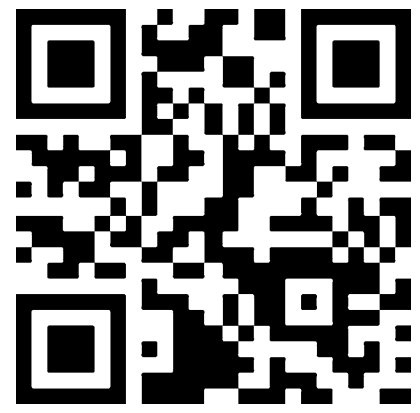

authors and the number of citations. "Differences among groups of authors with LATAM and non-LATAM affiliations and citations, journal $h$-index and the number of authors" section presents the ANOVA results by comparing citations, the journal $h$-index, and the number of authors, classified in two affiliation groups: lead authors with a LATAM affiliation and lead authors with a non-LATAM affiliation. "Top 20 most-cited articles and most productive institutions" section analyzes the top 20 most-cited articles and most productive institutions. And "Text mining of documents titles and co-authorship network" section presents the text mining of document titles and the co-authorship network.

\section{Publishing market, citations and $\boldsymbol{h}$-index distribution, and authors-citations correlation}

Overview information provided by SciVal for 2014-2018, found that 610 documents were published by 1565 authors producing a citation count of 3131, and 74 documents (12\%) were published in the top $10 \%$ most cited publications worldwide. Six publishing groups represent $65 \%$ of the market publications (Fig. 2). One in four articles were published in the journal Espacios, published by Consejo Nacional de Investigaciones Científicas y Tecnológicas (CONICIT), Venezuela (it is different from CONICIT, Costa Rica).

No single document with innovation as the keyword was published between 1984 and 1988, representing the longest absence of the subject (5 years); followed by 1993-1995,

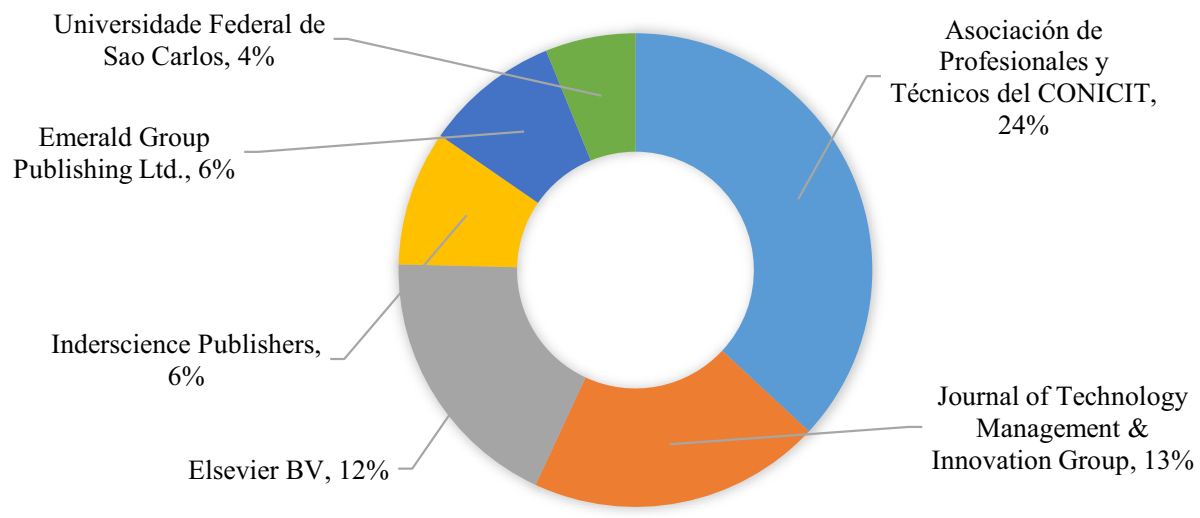

Fig. 2 Participation percentage of the publishers Source: Scopus (2018) and SCImago (2018) 
the second longest (3 years); and 1997 and 1999. After these absences, came the eruption: since 2000, the average annual publishing rate had increased $321 \%$ annually. This production peak has not been translated into impact as $46 \%$ of the documents have no single citation.

Documents were segmented according to their $h$-index (i.e., $h$-index $>100, h$-index 99>50 and $h$-index < 49) rather than quartiles (i.e., Q1, Q2, Q3 and Q4) given that some journals could be in Q1 either with a relatively low or a very high $h$-index. For instance, journals such as "E a M: Ekonomie a Management" was ranked in Q1 in BMA during 2014-2015 with an $h$-index of just 16, whereas the Academy of Management Journal, also ranked in Q1, has an $h$-index of 266. There is no point of comparison. To clarify, an entity, whether an author or a journal, has an index of $h$ if $h$ of the author's or journal's articles have at least $h$ citations each and the remaining articles have $\leq h$ citations each (Hirsch, 2005). The mean $h$-index was 31.6. Figure 3 shows that both trends of documents (articles and proceedings) published from 1998 to 2017 with an $h$-index $>100$ and between $99>50$ have been virtually stationary; the increase came from documents published in either journals or proceedings with an $h$-index $<49$. In fact, more than 300 documents were published in sources with an $h$-index of 6.

Concerning citation distribution, the mean number of citations in documents is 5.2, although 618 (46\%) documents have no single citation, of which 226 (36\%) were published in Espacios. By removing Espacios from the sample, the average number of citations increased from 5.2 to 6.6 (26\%). Two-hundred and twenty-one documents (16\%) only have one citation. The older documents tend to lump together most of the citations. Figure 4 shows that the number of citations/documents has progressively been decreasing since 2000, going from 33.47 cites/documents for the period of 2000-2002 to 1.5 for 2015-2017.

Besides the research output published in journals with $h$-index $<49$, the number of authors by article has remained virtually unchanged. The average number of authors in the first half of the articles published from 1983 to $2013(n=605)$ was 3.07, whilst the average number of authors in the second half from 2013 to $2018(n=606)$ was 3.1.

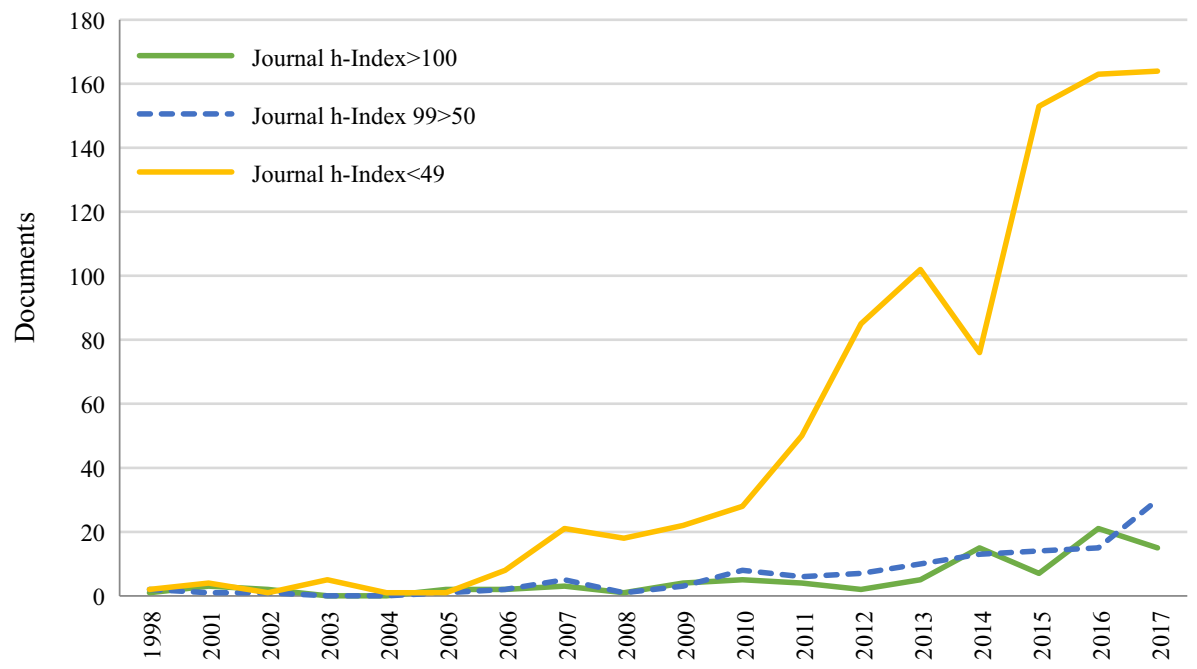

Fig. 3 Articles and proceedings published from 1998 to 2017 according to the $h$-index of the journal or proceedings Source: Scopus, 2018 \& SCImago 2018 


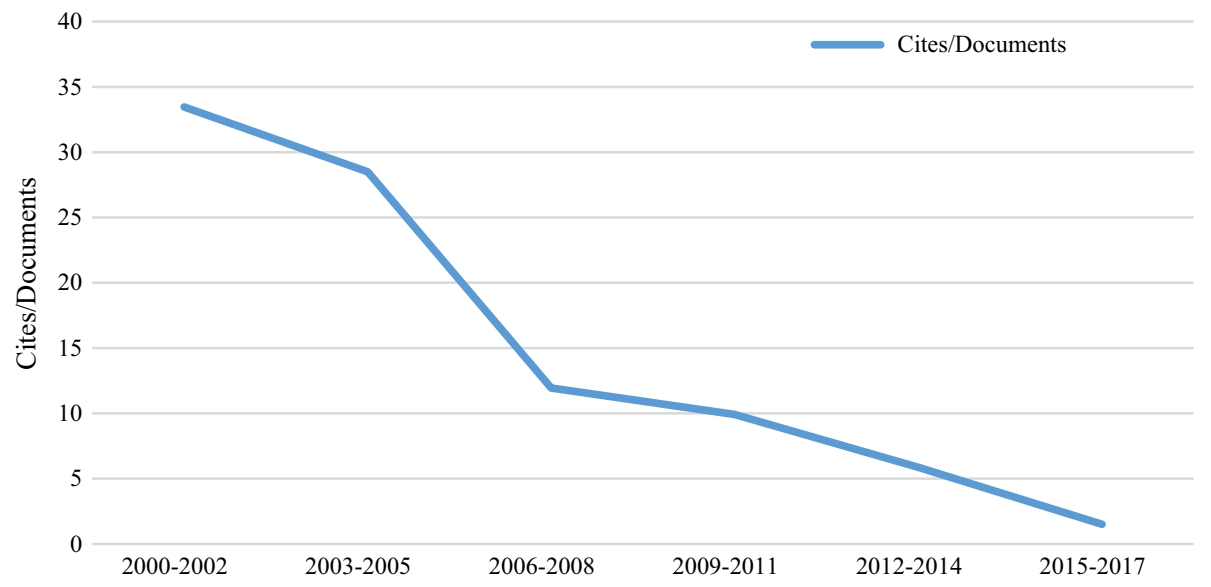

Fig. 4 Cites/documents from 2000-2017 Source: Scopus (2018) and SCImago (2018)

Correlational analysis showed no correlation between the number of authors and cites $(r=-.07 ; p<.05)$. There was no correlation $(r=0)$ between the number of authors and journal/proceedings' $h$-index wherein the articles were published.

Regarding academic-corporate collaboration information provided by SciVal for 2014-2018, there were seven documents (1.1\%) found. Table 3 displays the overview of these publications. These research topics were related to export diversification trough firm innovation, organizational practices in different cultures, and UniversityIndustry relations, among others. Some of the corporate-related authors were affiliated with institutions such as Petrobras, the Central Bank of Chile, Morgan Stanley, and Accenture. The mean $h$-index for this subset was 73 .

\section{Differences among groups of authors with LATAM and non-LATAM affiliations and citations, journal $h$-index and the number of authors}

Three ANOVA tests were conducted comparing citations, journal $h$-index, and number of authors by two affiliation groups: (1) leading author with a LATAM affiliation $(n=1065)$; and (2) leading author with non-LATAM affiliation $(n=146)$ (e.g., Spain [24\%], United States [16\%], or the United Kingdom [10\%]). The ANOVAs comparing citations $[F(1,1209)=23.496, p=.000]$ and journal $h$-index $[F(1,1209)=99.472$, $p=.000]$ by affiliation groups were significant. In consequence, the mean scores in citations and journals' $h$-index for documents published by the group with a leading author with a non-LATAM affiliation (citations: $\bar{x}=13, \sigma=17.1 ; h$-index: $\bar{x}=62.8, \sigma=55.1$ ) were significantly different than the group with a leading author with a LATAM affiliation (citations: $\bar{x}=4.4, \sigma=20.3$; $h$-index: $\bar{x}=27.3, \sigma=41.9$ ). There were no significant differences among groups comparing the number of authors $[F(1,1209)=3.478$, $p=.062]$. 


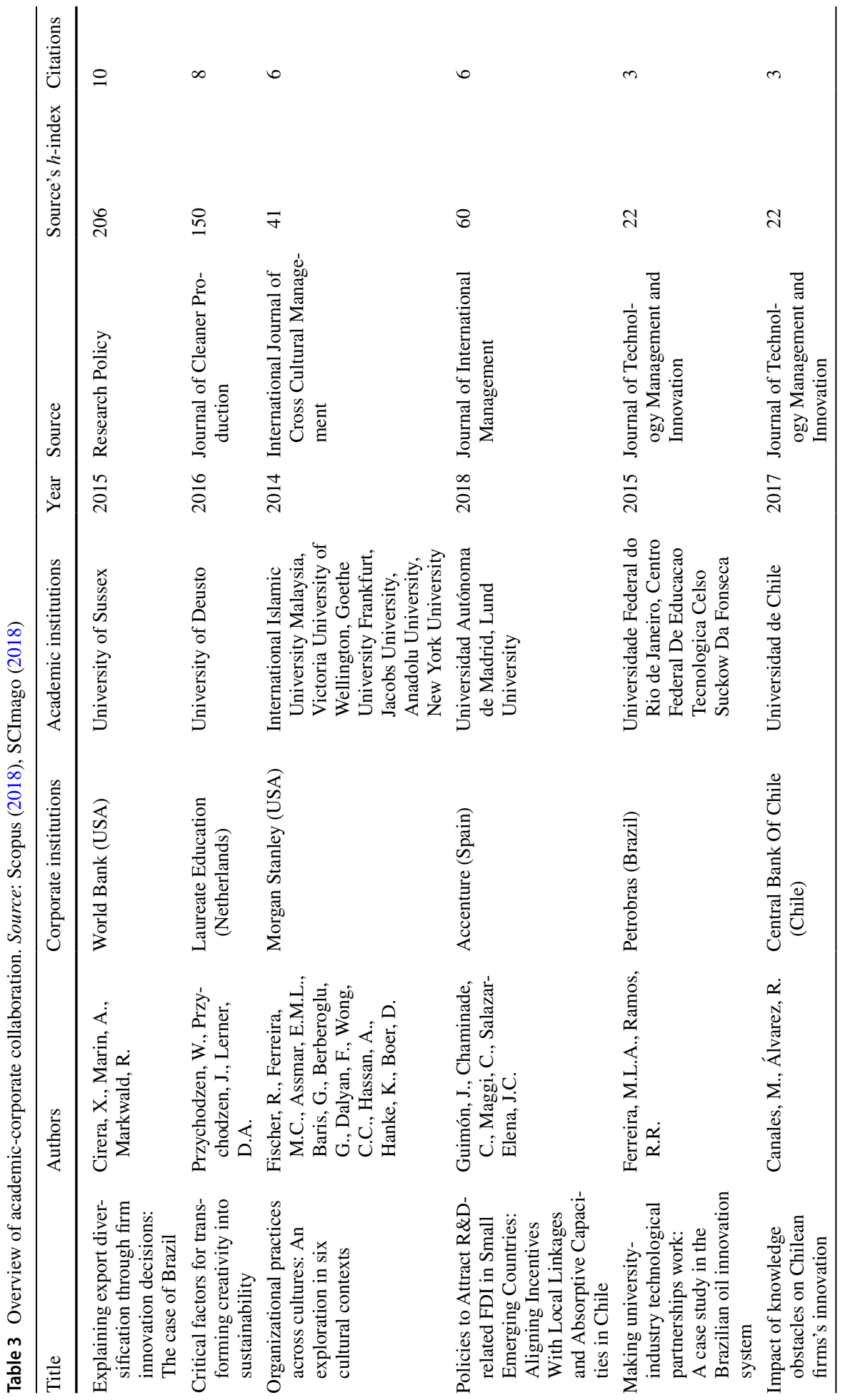




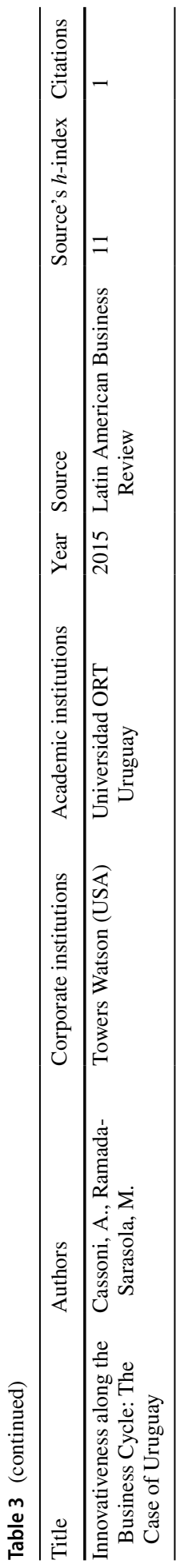




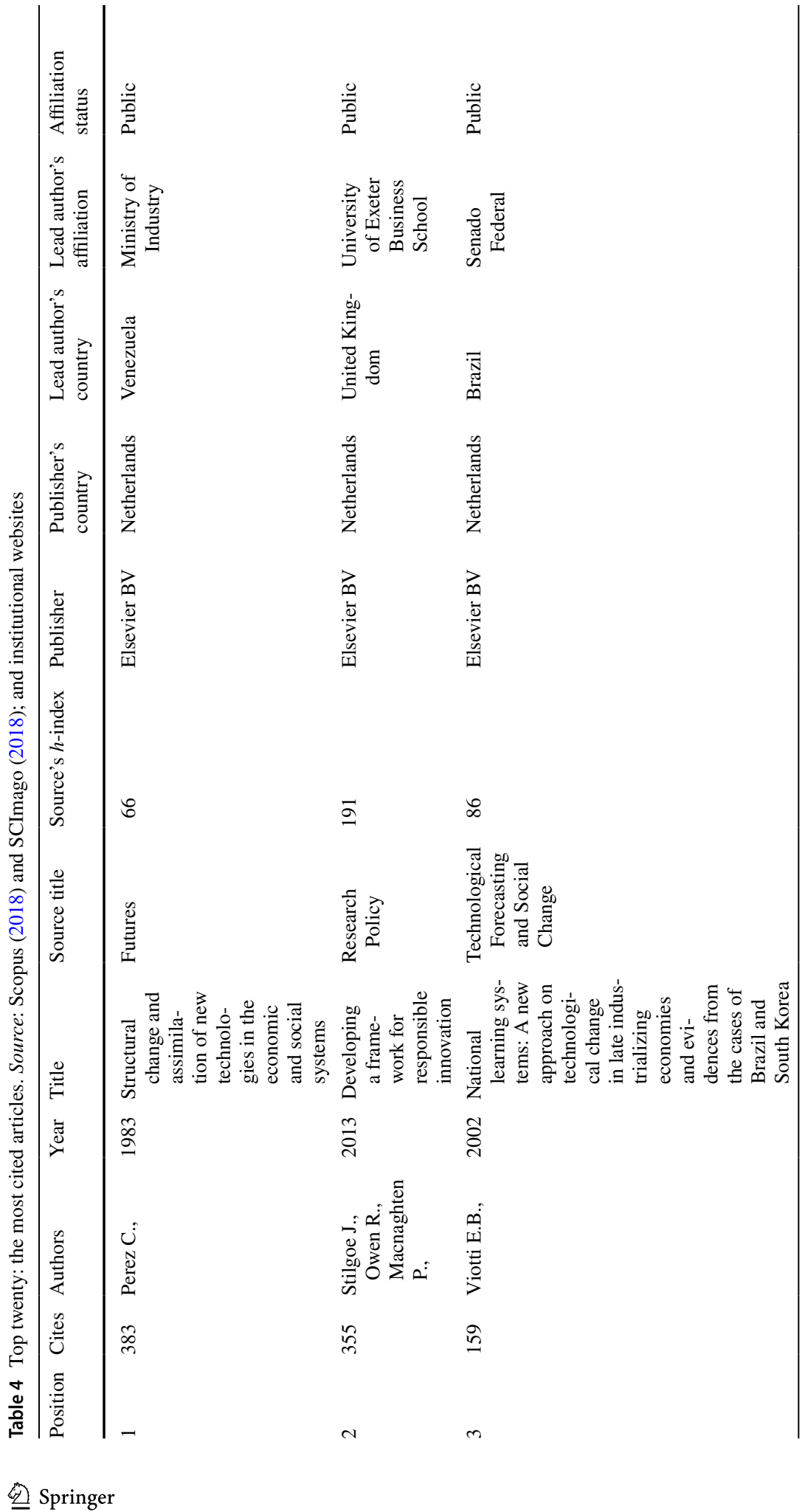




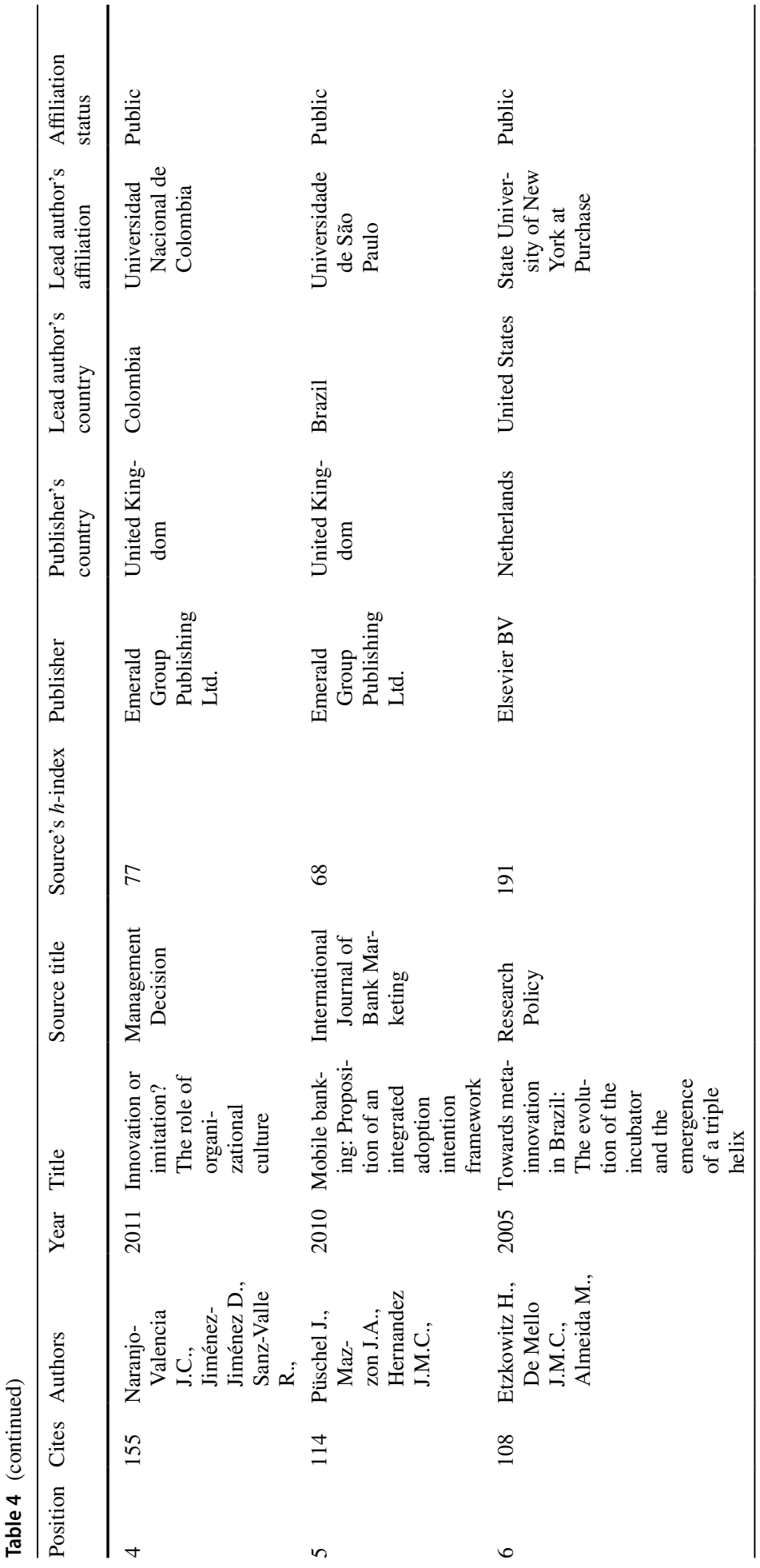




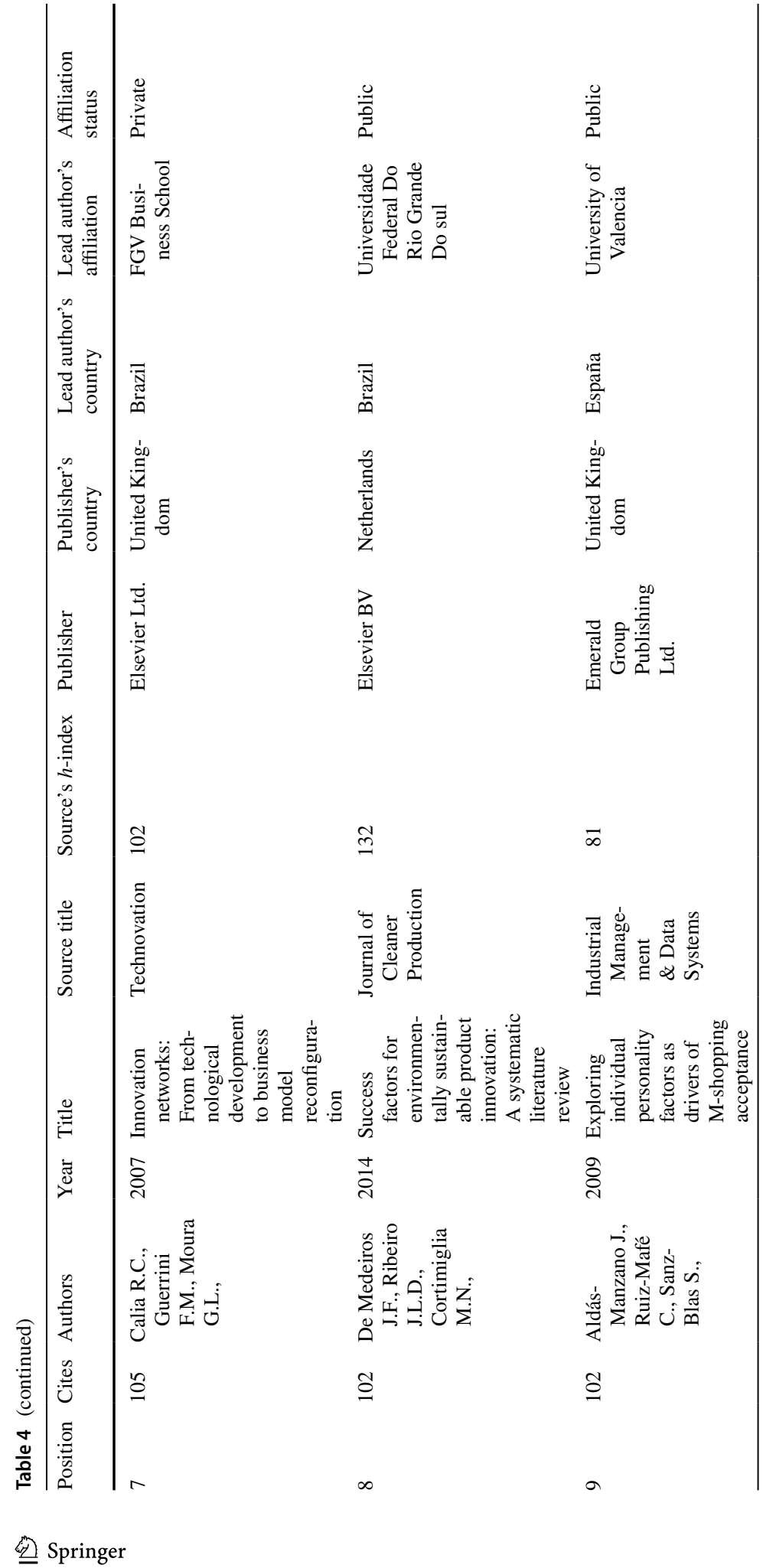




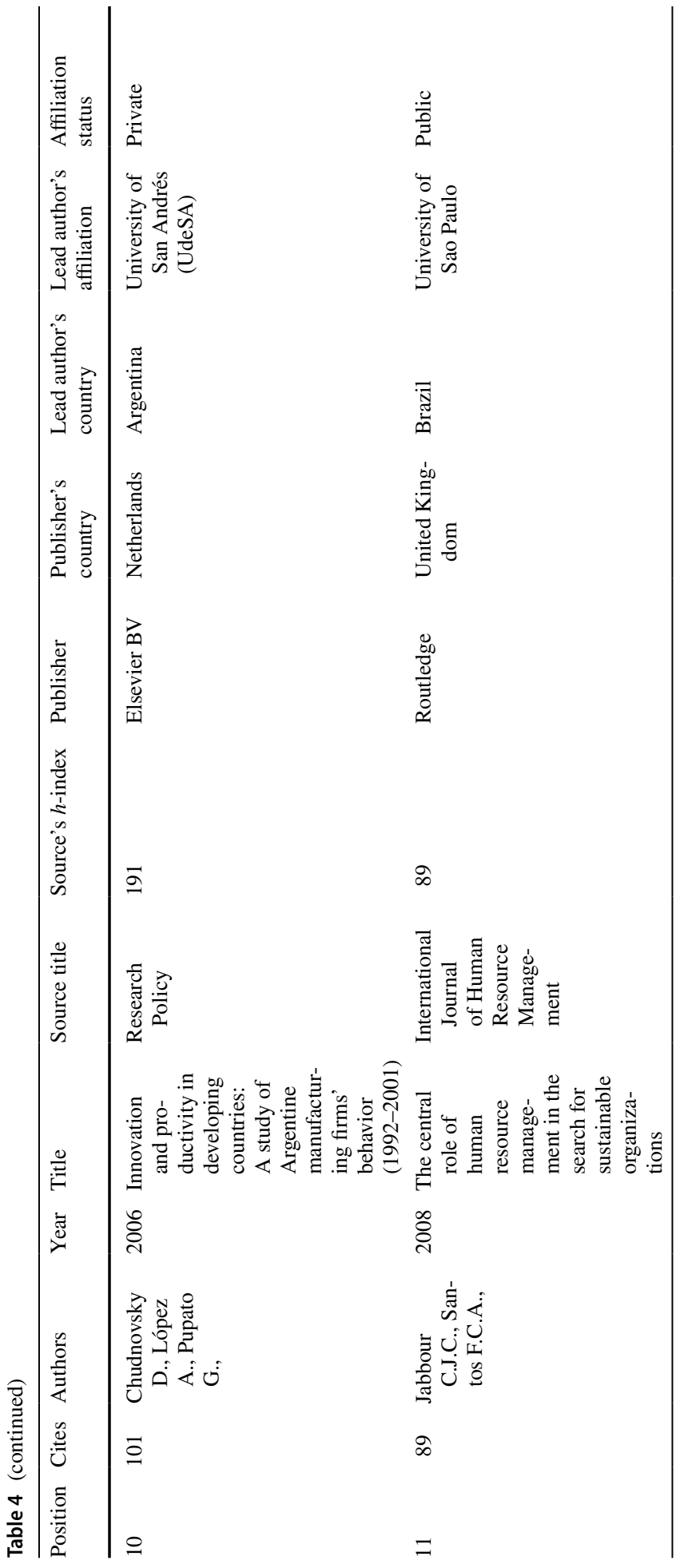




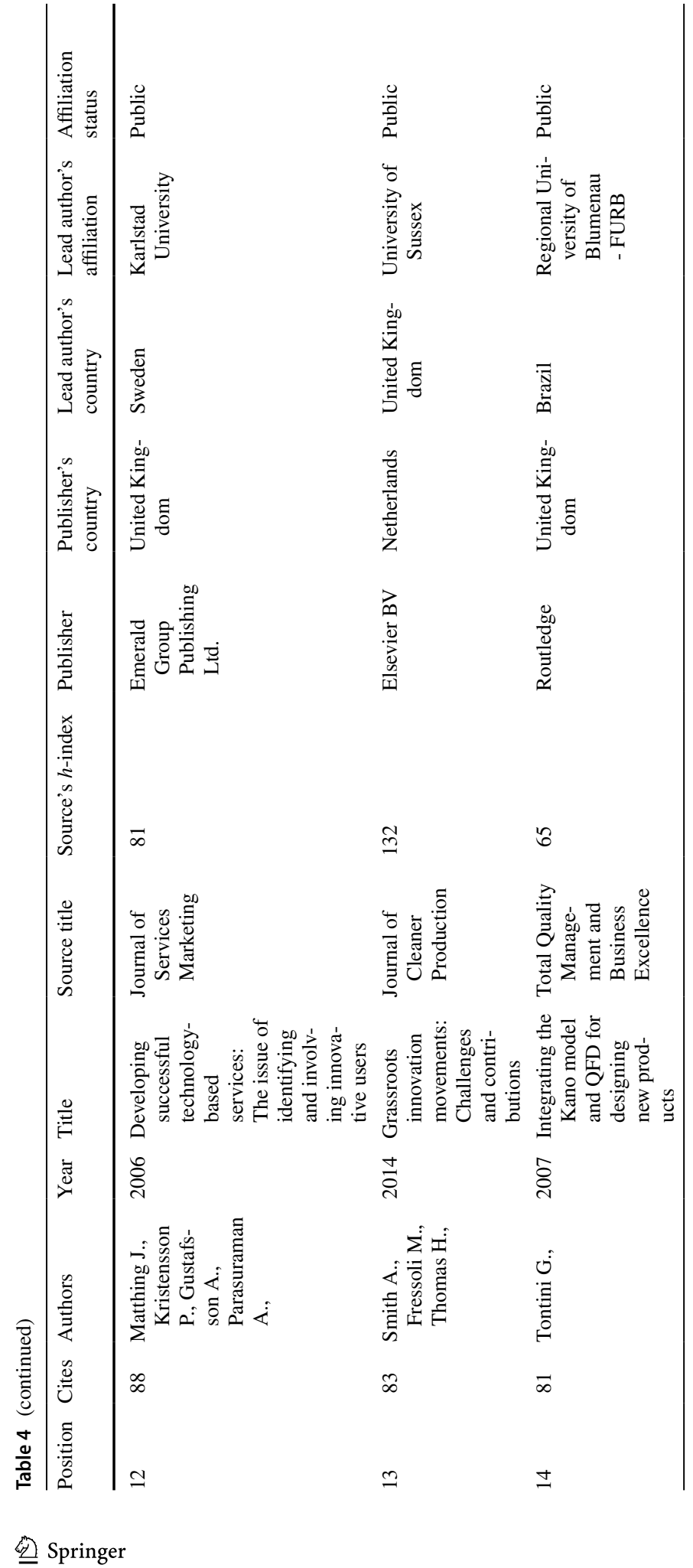




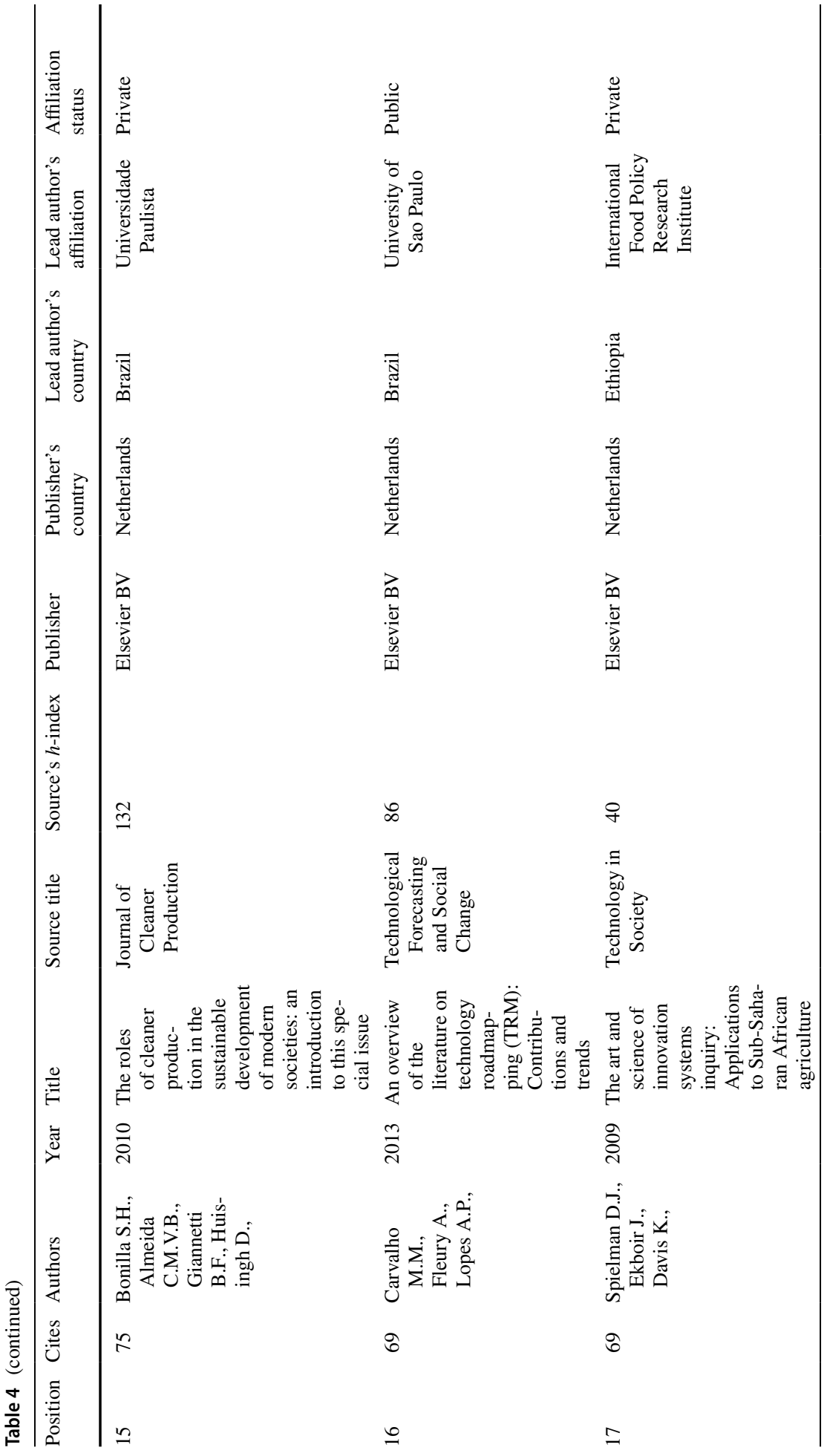




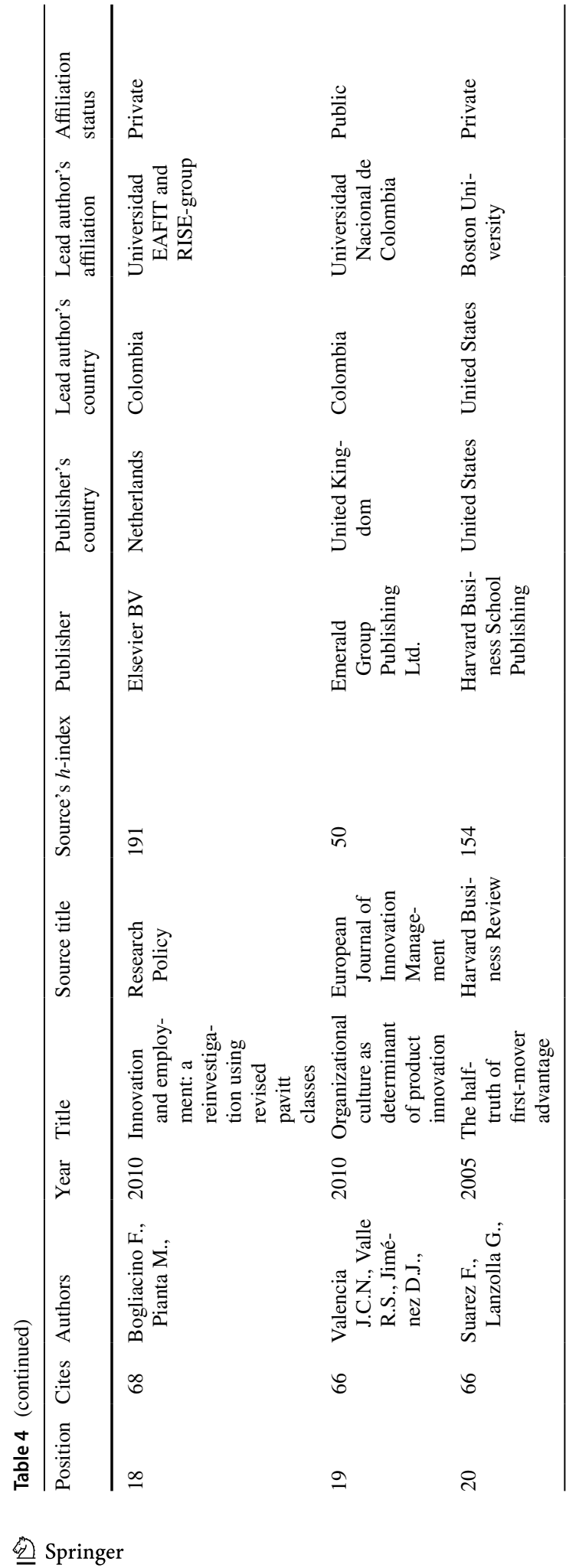




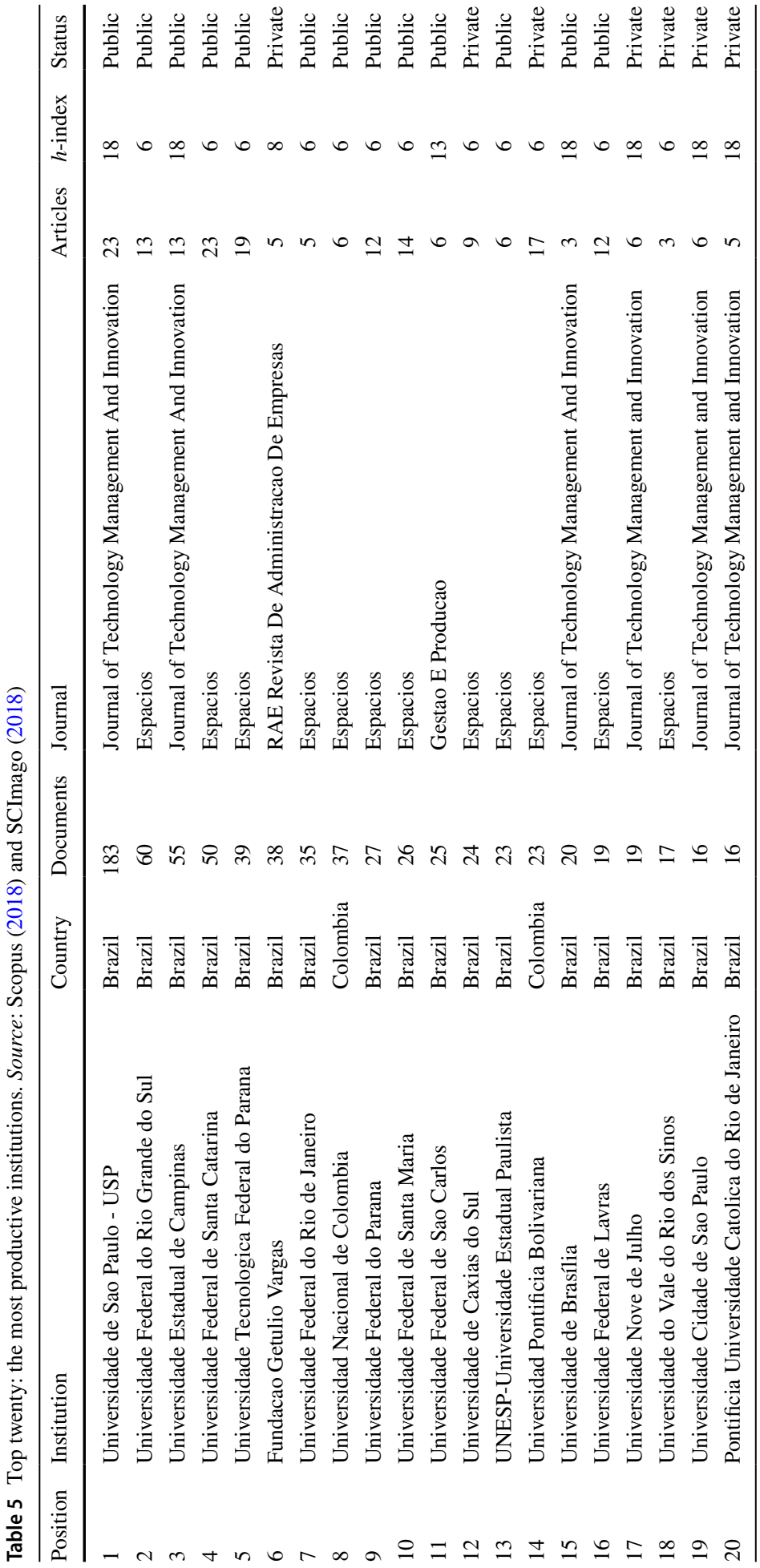




\section{Top 20 most-cited articles and most productive institutions}

Table 4 presents the list of the 20 most cited papers in the sample. Eleven articles (55\%) were led by authors from Brazil ( 8 articles) and Colombia ( 3 articles). Fourteen lead authors $(70 \%)$ were affiliated with a public organization, mainly with the University of Sao Paulo, with three articles in the top 20. Elsevier owned $60 \%$ of the journals (e.g., Futures or Research Policy), followed by Emerald Group Publishing with 25\% (e.g., Management Decision or International Journal of Bank Marketing). The average $h$-index of the journals is 91. The article: "Structural change and assimilation of new technologies in the economic and social systems" published in Futures is the most cited paper in the field in LATAM with 383 citations. It was authored by Perez, C. in 1983 when she was affiliated with the Ministry of Industry in Venezuela.

Table 5 presents a list of the 20 most productive institutions. The total number of articles published by these top 20 institutions is 752 (56\% of the sample). Sixty-five percent are public institutions. Ninety percent of the institutions are located in Brazil (e.g. Universidade de Sao Paulo or Universidade Federal do Rio Grande do Sul) and 10\% in Colombia (e.g., Universidad Nacional de Colombia and Universidad Pontificia Bolivariana). One out of four articles published by the top 20 institutions was published by Universidade de Sao Paulo (Brazil). In sixty percent of the institutions, the journal where manuscripts were submitted the most was Espacios (Venezuela), followed by Journal of Technology Management and Innovation (Chile) with 30\%. The average $h$-index of the journals that were mostly used for publishing is 11.2. Only two institutions appear in both rankings: Universidade de Sao Paulo and Universidad Nacional de Colombia.

\section{Text mining of documents titles and co-authorship network}

A text mining of 1330 documents' titles (21,340 words) was conducted using VOSviewer. VOSviewer allows for creating maps based on text data (i.e., a co-occurrence map). Binary counting was considered: the presence or the absence of a term in a given text is calculated, independently of its number of occurrences. The minimum number of occurrences of a term to be included in the co-occurrence map was ten, therefore of the total of 3338 terms identified, 71 met this threshold. Several terms were omitted to reduce noise (e.g., countries and some nouns such as analysis, effect, perspective). Figure 5 presents the network visualization of co-occurrence terms and Table 6 presents the clusters by colors and top-five cooccurrence terms according to their link strength attribute: the total strength of the links, or co-occurrences, of a given term with other terms. The following analysis is focused on the key terms with the highest link strength of the top-three clusters and the new research key terms. Co-authorship network presented in Fig. 6 highlighted the prominence of authors affiliated with Brazilian institutions. Seventeen communities of authors (i.e., clusters) were identified. The largest community of authors comprised 21 members in which both Jabbour, C. (Montpellier Business School, France - H Index: 31) and Jugend, D. (UNESPUniversidade Estadual Paulista, Brazil - H Index: 7) were the members with the highest number of co-authors (red cluster). The following cluster comprised 13 members, related trough Gomes, C. (Universidade Federal de Santa Maria, Brazil - H Index: 5) and Kruglianskas, I. (Universidade de São Paulo, Brazil - H Index: 8) (green cluster).

Innovation and knowledge are both key-terms highly related to management (i.e., total quality management, supply chain management, environmental management). Therefore, 


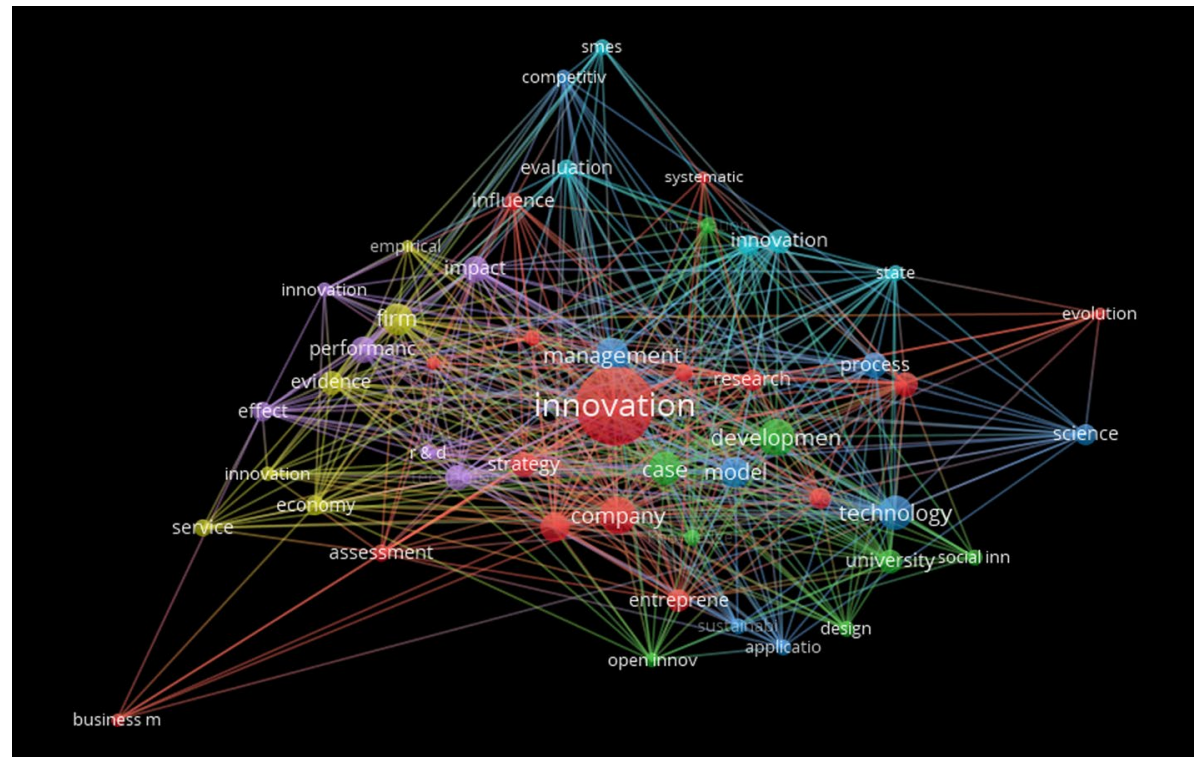

Fig. 5 Network visualization of co-occurrence terms. Source: author's own, based on Scopus (2018) and using VOSviewer

Table 6 Clusters by colors and top-five co-occurrence terms. Source: author's own, based on Scopus (2018) and using VOSviewer

\begin{tabular}{|c|c|c|c|c|c|}
\hline \multicolumn{2}{|c|}{ Cluster 1 (16 iterms) } & \multicolumn{2}{|c|}{ Cluster 2 ( 8 items) } & \multicolumn{2}{|c|}{ Cluster 3 ( 8 items) } \\
\hline Term & Link strength & Term & Link strength & Term & Link strength \\
\hline Innovation & 528 & Development & 138 & Technology & 139 \\
\hline Company & 178 & University & 66 & Management & 121 \\
\hline Case study & 106 & Knowledge management & 29 & Science & 67 \\
\hline Strategy & 62 & Innovation process & 22 & Application & 27 \\
\hline Knowledge & 56 & Open innovation & 21 & Sustainability & 27 \\
\hline \multicolumn{2}{|c|}{ Cluster 4 (6 items) } & \multicolumn{2}{|c|}{ Cluster 5 (6 items) } & \multicolumn{2}{|c|}{ Cluster 6 (6 items) } \\
\hline Term & Link strength & Term & Link strength & Term & Link strength \\
\hline Firm & 111 & Impact & 85 & Network & 50 \\
\hline Evidence & 64 & Innovation performance & 79 & State & 40 \\
\hline Economy & 48 & Technological innovation & 64 & Evaluation & 39 \\
\hline Innovation capacity & 23 & $R \& D$ & 29 & Innovation system & 36 \\
\hline Service & 21 & & & SMEs & 20 \\
\hline
\end{tabular}

both innovation and knowledge are resources to be managed. The titles expressed the relevance of either individual or multiple cases (studies) as methodological appraisal. The cases were not only focused on individual firms (e.g., a food company) but on countries (e.g., Brazil), regions (e.g., north-west of Bolivia), sectors (e.g., industrial sector), companies (e.g., ceramic cluster) or products (e.g., cameras). Development was mostly related to the development of firms, new technologies or products. In some cases, development was either sustainable or inclusive. Several studies referring to Technology were on road mapping, foresight, and future-oriented studies. The adoption and diffusion of technologies were also relevant topics among the most cited literature. In the case of University, studies were mostly concerned with the relation between University-Industry/Firms/Business and other paths of action towards an entrepreneurial university. 


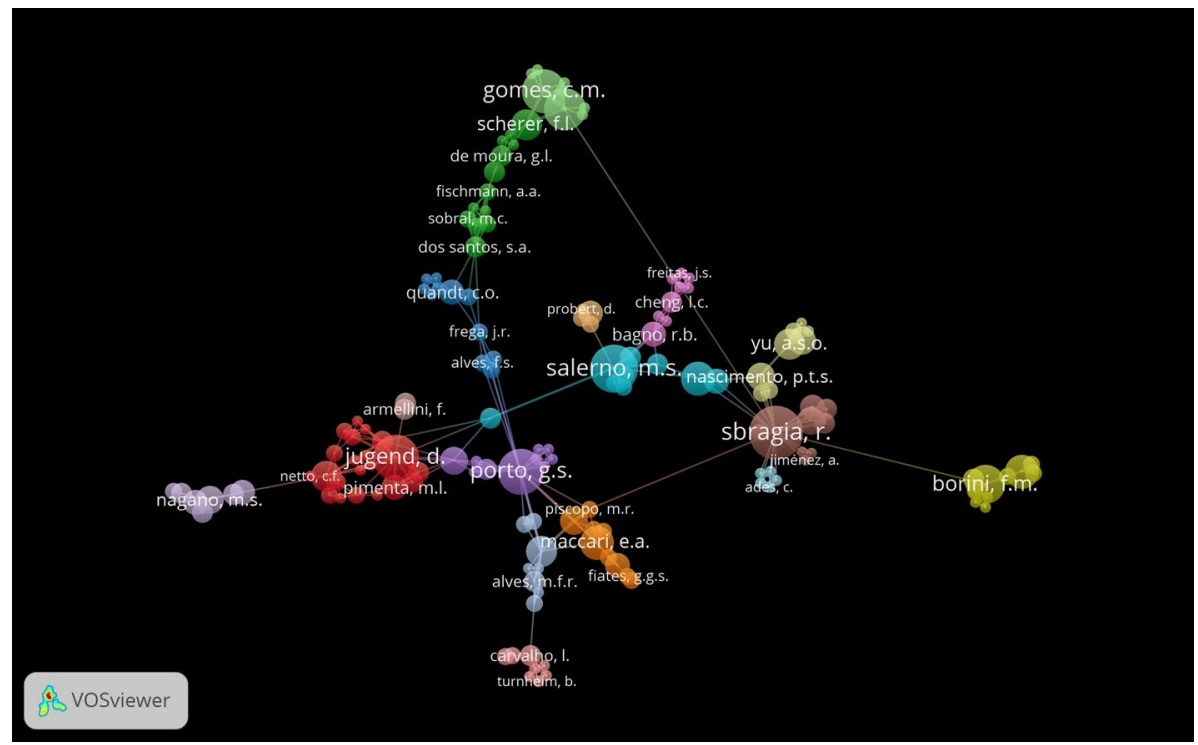

Fig. 6 Co-authorship network. Source: author's own, based on Scopus (2018) and using VOSviewer

In recent years (2014-2018), two topics have figured as emergent: absorptive capacities and social innovation. As stated by Cohen and Levinthal (1990, p. 128) in their seminal study, absorptive capacity is a firm's "ability to recognize the value of new, external information, assimilate it, and apply it to commercial ends". This capacity is crucial for innovation in BMA. Nevertheless, this topic figured as emergent in the LATAM context. Its first study was published in 2015, 25 years after that of Cohen and Levinthal (1990). One of the earliest references to social innovation in BMA, on the other hand, was proposed by Kanter (1999) (Phillips et al. 2015) who defined it as a perceived opportunity by society's private sector to develop ideas and innovations that produce both market and community benefits. In LATAM, this topic gained importance until 2013, 14 years after Kanter's contribution. As noted, research topics pointed as emergent in LATAM in the last 5 years, have been in the literature for more than a decade.

\section{Discussion}

Several countries in the region remain with no intellectual production on innovation in BMA. Specifically, six out of 20 countries, namely: Dominican Republic, El Salvador, Guatemala, Honduras, and Haiti. Hence, most of Central America and the Caribbean regions are falling behind the rest of LATAM. This distancing might create a profound inter-regional gap, as countries such as Brazil and Colombia published $80 \%$ of the documents in the region.

The article was the main pathway for research diffusion as $83 \%$ of the sample's documents were comprised of articles and only $0.1 \%$ of books. When it was asked to 20,000 members of the Academy of Management on indicators of scholarly impact and beneficiaries for institutional support, they answered to the former: (1) scholarly articles in top-tier 
Question Asked 4 years ago

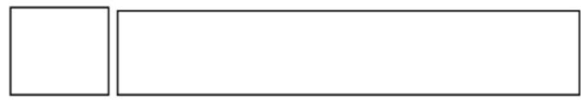

\title{
Does your institution pay you in case you publish your research in some of the leading journals?
}

\author{
In Turkey, there is such a system of payment (awarding) for supporting researches \\ published in some of the SCI/SSCl indexed journals. See the attachment. \\ I would be happy to hear if there is such a system in your country? \\ DUBYT_2014_dergi_listesi_v2.xIs $\cdot 2.24$ MB \\ Support of Research Scientific Research Scientific Publishing
}

Fig.7 Question on publishing incentives in Research Gate. Source: Research Gate (2014)

journals, and (2) scholarly citations in others' research; and the latter: (1) publication in top-tier journals, (2) scholarly citations by others, (3) obtaining research grants, (4) published books, and (5) publication in practitioners' journals (Haley et al. 2017). Another reason for the scarce presence of books is the general unavailability of books on academic platforms. This is, nonetheless, in the process of changing. For instance, since the initiation of the Book Titles Expansion program of Scopus in 2013, the goal of indexing 75,000 books has been reached (Elsevier 2013). Up to 2016, 120,000 books were already indexed.

Globally, the English-language has become the default academic language. In fact, $72 \%$ of the documents we used were published in English and only 12\% in Spanish. Simply put, if a scholar from a non-Anglophone country, as in LATAM, does not publish research in English, he or she has become merely a consumer of knowledge instead of a producer of it (Tardy 2004). Incentives are also behind this. English-medium publishing is a bonus for tenure and academic promotion (Bocanegra-Valle 2014). For instance, Fig. 7 shows a question asked in a ResearchGate forum 4 years ago on publishing incentives. The person who asked also uploaded a list of financial incentives according to journals in the case of Turkey. The average incentive for publishing in management-related journals was US $\$ 638$, the equivalent of 2.6 the minimum wage in Turkey (i.e., 11600 up to 2018). Hence, the mot: "Publish or perish" is incomplete. A better version would be: "Publish in English or perish".

The dominant countries of (and out of) LATAM were Brazil and Spain. During the past 22 years, both Brazil and Spain published 33,471 documents in BMA, representing 65\% of the overall publications in Ibero-America (Cortés-Sánchez 2018a). The absence of research in the field that took place between 1984 and 1988, could have been caused by, among others, the Década Perdida (The Lost Decade): a period of major financial crisis in the region. Arocena and Sutz (2001) outlined a regional diagnosis on several and multidimensional constraints for innovation during the period, such as: (1) the stagnation of the budget of public universities (for instance, the numbers in Chile were shocking as the public budget for higher education dropped by $37.2 \%$ ); (2) the low importance given to endogenous 
knowledge production and the low involvement of industry with R\&D; and (3) the 'structurally unachieved' building of National Systems of Innovation.

Concerning the market participation of the publishers, it raised a major concern. Larivière et al. (2015) found that only five publishers account for more than $50 \%$ of all papers published in 2013 (e.g., Reed-Elsevier and Wiley-Blackwell). In spite of this, for a researcher, it is feasible to relate journals of Elsevier such as Research Policy to top-tier research on innovation. In LATAM the scenario is frustrating. One out of four papers were published by CONICIT. Unlike the association between Elsevier-Research Policy, the only journal CONICIT publishes is Espacios. As the author of this study has publicly stated (Cortés-Sánchez 2018a, b), this journal has several characteristics of a predatory journal (Shamseer et al. 2017; Beall 2015) despite being indexed in Scopus, such as: poor web design; (hyper) short time for peer reviewing and publishing (sometimes it takes less than a week for publication); low processing charge (US\$150) considering that the average article processing charge in the Directory of Open Access Journals is US\$964 and the mode is US\$0 (Morrison et al. 2015); and exponential rate of publishing (only in 2017, more than 1700 articles were published) (SCImago 2018). The approximate calculation was US $\$ 255,000$ of income for Espacios only in 2017. The explosion of articles published in journals with an $h$-index $<49$, mostly emanates from Espacios ( $h$-index of 6). Regardless of the proliferation of English-language publications in LATAM, the $h$-index journals overall trend has been diminishing throughout the years.

Furthermore, the detonation of output does not correlate with neither visibility nor impact. Forty-six percent of the documents do not have a single citation, which is a number close to that stated by Hamilton (1990) of 55\% of the papers published never being cited after 5 years, and way far from that stated by the same author of $77 \%$ of the papers on business never being cited after 4 years of their publication (Hamilton 1990). Only six percent (220) of the documents have received at least one citation. As time has passed, the relation between cites/documents has been decreasing to the minimum in 2017. The undisputed outliers were the studies entitled "Structural change and assimilation of new technologies in the economic and social systems" and "Developing a framework for responsible innovation", authored by Perez (1983) and Stilgoe et al. (2013) respectively, with 383 and 355 cites each.

Research on University-Industry relation is a different tale from academic-corporate collaboration. In terms of net output, while 23 documents on the relation between University-Industry/Enterprise/Firm have been published since 2000s (e.g., Sutz 2000; Zawislak and Dalmarco 2011) only seven have been published with at least one co-author affiliated with a corporation since 2014 (e.g., Cirera et al. 2015; Przychodzen et al. 2016). An interesting aspect to be highlighted, is that regardless of the little involvement of corporate organizations as co-authors, those organizations figured as either one of the biggest firms in the sub-continent (i.e., Petrobras), a national bank (i.e., Central Bank of Chile), or major multinational companies (i.e., Accenture). Also, the articles published by the latter group are being published in journals with a mean $h$-index (73) way above the mean $h$-index index of the whole sample (31.6). Sutz (2000) outlined several strategies to improve the University-Industry relation in the LATAM context, worth mentioning in this study, such as the exchange of information between Universities-Industries concerning capacities for problem solving and knowledge needed from both sides, focusing on some type of enterprise branch to raise competence pools between faculty and firms, and more legitimization that both actors can achieve gains from their joint strategies.

Individual researcher as a lone-wolf type is decreasing, even more as doing big-science (De Solla Price 1963) would be the next port to reach. In spite of that, the number of authors by paper (i.e., as a proxy of the social capital and collective work on research 
developing and publishing) in the sample studied remains unchanged. Wuchty et al. (2007) argued that over the past 45 years, the average number of authors per paper has increased from 1.9 to 3.5. In the subject of management, Acedo et al. (2006) found that the average number of co-authors in the subject was 2.8. On innovation related-studies, Lazzarotti et al. (2011) identified an average of 1.8 authors by article. In this study, the average number of authors of the nine papers published prior to 2000 was 1.8. Hence, after 2000 the average increased in 1.2 authors per paper, from 1.8 to 3.07. This average is approximate to that of Acedo et al. (2006). Nevertheless, the sample prior to 2000 is too small to conclude anything. Acedo et al. (2006) also found that articles with two authors seem to have a greater impact, yet in this study no correlation was found between either number of authors and cites, or number of authors and $h$-index wherein articles were published. Similar conclusions were pinpointed in the field of chemistry since no correlation was found between the strength of a co-authorship and the relative citation eminence (Glänzel and Schubert 2001). Comparing citations, journal $h$-index, and number of authors by lead authors from LATAM and non-LATAM countries, resulted in significant differences. A document featuring a leading author outside LATAM is usually more cited and published in a journal with a higher $h$-index. This reinforces the thesis that foreign English-written research is more consumed by peripheral regions, such as LATAM (Tardy 2004).

Lead authors from Brazil and Colombia domain the top 20 most cited articles in the field. Both countries are the most productive as well as the most visible in terms of citations. It is also remarkable the dominance of public institutions in both countries, regardless of the lack of government funding for research and development (R\&D) activities. From 2006 to 2016, the annual R\&D investment in Colombia was $0.2 \%$ of GDP on average, meanwhile in Brazil was 1.1\% from 2006 to 2015 (The World Bank 2018). On the other hand, public investment in tertiary education (i.e., public universities listed in the top 20), as well as the percentage of public expenditure on education in both countries, have considerably increased. From 2008 to 2017 that percentage was $20.7 \%$ per year on average in Colombia, meanwhile it was 17.4\% from 2006 to 2015 in Brazil (The World Bank 2018). It seems that financial resources for higher education have been fundamental for the research in innovation in LATAM and its related impact. It is crucial to observe, nonetheless, that a proportional relationship between $R \& D$ activities and their research impact is not clearly established. For instance, in the health sciences field, Jacob and Lefgren (2011) estimated that a receipt of a National Institute of Health research grant leads to only one additional publication over the next 5 years and a small effect on further citations.

Elsevier owned $60 \%$ of the journals in the top 20. This percentage is similar to the $70 \%$ of articles published by only five editorials (i.e., Reed-Elsevier, Wiley-Blackwell, Springer, and Taylor \& Francis) in social sciences (Larivière et al. 2015). Indicators of scholarly impact and beneficiaries of institutional support are anchored in publications in top-tier journals, that are partly owned by those same editorials. Same journals and editorials will maintain their oligopoly as researchers on the field they seek (and dream about) to get published as well as being read and cited in those same journals. Nevertheless, the current situation in the region is far more endogenous. The most productive institutions keep publishing most of their research in regional journals, one of them with evident predatory features (i.e., Espacios). Regardless of the comparative advantage they have for being open access journals, the average $h$-index of the most used journals of the region is almost a tenth of the average $h$-index of the journals in the top 20 .

Previous text mining studies conducted at a regional level have shown a few similarities. Favaretto and Francisco (2017) conducted a text analysis of the archive of the journal Revista de Administração de Empresas (Journal of Businesses Administration) from 
1961 to 2017. By comparing the most used words in article titles among both that and this study, a similarity was found among administração or gestão (administration or management) and caso (case). Indústria (industry) and tecnologia (technology) also appeared below the top-ten. The relevance of management of (and related to) innovation was also pinpointed by Lopes and De Carvalho (2012) and Ceretta et al. (2016). In addition, the link between (social) innovation and social entrepreneurship described by Silveira and Zilber (2017) was also found with additional particularities. Both key-terms social and entrepreneurship did not reach the top-ten but the top-50. Similarly, they were commonly related (e.g., How social entrepreneurs in the third sector learn from life experiences). Individually related, social appeared the most next to knowledge, technology and companies. In spite of its mutual companion, social was a key-term with more centrality and importance with innovation than entrepreneurship. There was no difference between the methodological appraisal (i.e., case) between management in general and innovation in particular. This might be one of the reasons it has been difficult for scholars from LATAM to publish in top-tier journals. We looked into 1667 articles of the Academy of Management Journal, and then searched for the key-term case among the articles' titles: only 23 explicitly mention the case as a methodological appraisal. To be highlighted, the most cited article of this journal is entitled: Theory building from cases: Opportunities and challenges with 4345 citations (Eisenhardt and Graebner 2007). This research aims to take a step further with the cases in order to emanate theory from them. Simply put, to reach top-tier journals, research from LATAM should propose theory-oriented research instead of case-based.

In terms of emergent topics in the last 5 years (i.e., absorptive capacities and social innovation), such topics have been in the body of literature of BMA for more than a decade. In LATAM, however, these have only been a matter of study since 2013. Topics related to Industry 4.0 that are going to be radically transformative for innovation in business in the upcoming years such as Artificial Intelligence, Big Data, Internet of Things, Smart Industry and Smart Manufacturing, Cloud Computing, among others, are not part of the current research agenda (Muhuri et al. 2019). This dearth of LATAM research from the frontiers of innovations in BMA suggests several concerns on the participation of the region in the conversation with researchers and institutions from the global north.

\section{Conclusion}

Research on innovation in BMA from LATAM has surpassed the expectations in terms of net output, yet its current impact and inter-regional gaps outline several concerns for the field in the upcoming years. First, six out of 20 countries from LATAM remain with no intellectual production on innovation in BMA. This detachment creates a profound inter-regional gap between Central America and the Caribbean, and the rest of the countries from LATAM.

Second, the BMA global-north scholars' community has always been a major influence for that of LATAM. Business and Management Schools in LATAM are increasingly pursuing international accreditations (i.e., AACSB) and standards, and this trend does not seem to be halting. An English-fluent faculty and articles both published and cited in top-tier journals (the majority published in English) are now one of the indicators for international accreditations and attractive incentives.

Third, the financial crisis of the 1980s known as The Lost Decade shocked and essentially muted the research on innovation in the region, followed by two more periods. 
Only after 2000, this research subject skyrocketed its intellectual production. In the last 18 years, one out of four articles has been published in a journal with several predatory features. In spite of this, this is a rounded business for editorials as such. And the business is bullish. The aftermath of this misadventure is that it might cause an unmeasured discredit for the future of research on innovation from the region. In addition, almost half of the articles published lack a single citation, and the relations cites/documents do not show any symptom of increasing, while the social capital remains static and inter-regional.

Fourth, management and innovation were the most strongly related key-terms of research. In addition, despite innovation, social, and entrepreneurship being related, social was the prominent, and also related to other relevant key-terms such as knowledge and technology. The case was noticeable as the methodological appraisal on innovation research on BMA by default, which is not the case in the top-tier journals as theoretical perspectives have been the most discussed. Recent research topics such as absorptive capacity and social innovation have been in the literature for more than 15 years and game-changing topics for innovation in BMA such as Industry 4.0 are not noticeable in the current co-occurrence map. The absence of intellectual production in LATAM on these topics might be a major concern for researchers, business schools, and research institutions in general, which limits their ability to participate in the global conversation of high-tech trends in BMA research.

The results obtained in this study provide an outlook to be considered for research evaluation entities and scholars on the subject of BMA and innovation. The open access dataset also allows for the replication or triangulation of the data in further studies, to locate influential studies or researchers, to measure inter-regional production gaps and topics of research, among either academic or practice-related interest. Future studies could compare the differences between different bibliometrics and scientometrics platforms, such as Google Scholar, WoS or Dimensions. Methodological appraisals such as co-authorship or co-citation analysis could also amplify the understanding of the researchers' social capital. Furthermore, comparative analyses considering additional groups of countries (e.g., Europe or Asia) would facilitate to place LATAM in a global perspective. Finally, one of the greatest unresolved questions is the cause of intellectual production backwardness in Central America and the Caribbean. Further studies should consider the identification of the root cause(s) of inter-regional inequalities, and the pathway for LATAM institutions to participate and contribute in research topics that are changing the innovation and business dynamics worldwide.

Acknowledgements The author would like to thank to Universidad del Rosario's School of Management. Also, thanks to Dr. Julia Jensen for her proofreading assistance.

Open Access This article is distributed under the terms of the Creative Commons Attribution 4.0 International License (http://creativecommons.org/licenses/by/4.0/), which permits unrestricted use, distribution, and reproduction in any medium, provided you give appropriate credit to the original author(s) and the source, provide a link to the Creative Commons license, and indicate if changes were made.

\section{References}

Acedo, F. J., Barroso, C., Casanueva, C., \& Galán, J. L. (2006). Co-authorship in management and organizational studies: An empirical and network analysis. Journal of Management Studies, 43, 957-983. https://doi.org/10.1111/j.1467-6486.2006.00625.x. 
Arocena, R., \& Sutz, J. (2001). Changing knowledge production and Latin American universities. Research Policy, 30, 1221-1234. https://doi.org/10.1016/S0048-7333(00)00143-8.

Baregheh, A., Rowley, J., \& Sambrook, S. (2009). Towards a multidisciplinary definition of innovation. Management Decision, 47, 1323-1339. https://doi.org/10.1108/00251740910984578.

Beall, J. (2015). Criteria for determining predatory open-access publishers, 3rd ed. https://goo.gl/ tmM3eC. Accessed July 1, 2018.

Birkinshaw, J., Hamel, G., \& Mol, M. J. (2008). Management innovation. Academy of Management Review, 33, 825-845. https://doi.org/10.5465/amr.2008.34421969.

Bocanegra-Valle, A. (2014). "English is my default academic language": Voices from LSP scholars publishing in a multilingual journal. Journal of English for Academic Purposes, 13, 65-77. https://doi. org/10.1016/j.jeap.2013.10.010.

Ceretta, G. F., Dos Reis, D. R., \& Da Rocha, A. C. (2016). Innovation and business models: A bibliometric study of scientific production on Web of Science database. Gestao E Producao, 23, 433444. https://doi.org/10.1590/0104-530X1461-14.

Cirera, X., Marin, A., \& Markwald, R. (2015). Explaining export diversification through firm innovation decisions: The case of Brazil. Research Policy, 44, 1962-1973. https://doi.org/10.1016/j.respo 1.2015.06.004.

Cohen, W. M., \& Levinthal, D. A. (1990). Absorptive capacity: A new perspective on learning and innovation. Administrative Science Quarterly, 35, 128-152. https://doi.org/10.2307/2393553.

Cortés-Sánchez, J. (2018a). Bibliometrics analysis of the most cited documents in business, management and accounting in Ibero-America. Bogotá: Universidad del Rosario.

Cortés-Sánchez, J. (2018b). Into oblivion: A closer look at the business, management and accounting research literature in Ibero-America. Retrieved from: https://goo.gl/jsUcgM. Accessed 22 Aug 2019.

De Carvalho, G. D. G., Cruz, J. A. W., De Carvalho, H. G., Duclós, L. C., \& De Fátima Stankowitz, R. (2017). Innovativeness measures: A bibliometric review and a classification proposal. International Journal of Innovation Science, 9, 81-101. https://doi.org/10.1108/IJIS-10-2016-0038.

De Paulo, A. F., Carvalho, L. C., Costa, M. T. G. V., Lopes, J. E. F., \& Galina, S. V. R. (2017). Mapping open innovation: A bibliometric review to compare developed and emerging countries. Global Business Review, 18, 291-307. https://doi.org/10.1177/0972150916668600.

De Solla Price, D. (1963). Little science big science... and beyond. New York: Columbia University Press.

Eisenhardt, K. M., \& Graebner, M. E. (2007). Theory building from cases: Opportunities and challenges. Academy of Management Journal, 50, 25-32. https://doi.org/10.5465/AMJ.2007.24160888.

Elsevier. (2013). Elsevier announces its Scopus book titles expansion Program. Retrieved from: https:// goo.g1/LMZTLn. Accessed 22 Aug 2019.

Favaretto, J. E. R., \& Francisco, E. R. (2017). Exploring the archive of RAE-Revista de Administração de Empresas (1961-2016) in the light of bibliometrics, text mining, social network and geoanalysis. Revista de Administração de Empresas, 57, 365-390. https://doi.org/10.1590/S0034-7590201704 07.

Gavel, Y., \& Iselid, L. (2008). Web of Science and Scopus: A journal title overlap study. Online Information Review, 32, 8-21. https://doi.org/10.1108/14684520810865958.

Glänzel, W., \& Schubert, A. (2001). Double effort=Double impact? A critical view at international coauthorship in chemistry. Scientometrics, 50, 199-214. https://doi.org/10.1023/A:1010561321723.

Haley, U., Page, M., Pitsis, T., Yu, K., \& Rivas, J. (2017). Measuring and achieving scholarly impact. Morgantown, WV: The Academy of Management.

Hamilton, D. P. (1990). Publishing by- and for? The numbers. Science, 250, 1331-1332. https://doi. org/10.1126/science.2255902.

Hirsch, J. E. (2005). An index to quantify an individual's scientific research output. Proceedings of the National Academy of Sciences of the United States of America, 102, 16569-16572. https://doi. org/10.1073/pnas.0507655102.

Jacob, B. A., \& Lefgren, L. (2011). The impact of research grant funding on scientific productivity. Special issue: The role of firms in tax systems, 95, 1168-1177. https://doi.org/10.1016/j.jpube co.2011.05.005.

Kanter, R. M. (1999). From spare change to real change: The social sector as beta site for business innovation [WWW document]. Harvard Business Review. http://link.galegroup.com/apps/doc/A5455 6303/AONE?sid=googlescholar. Accessed June 25, 2019.

Larivière, V., Haustein, S., \& Mongeon, P. (2015). The Oligopoly of academic publishers in the digital era. PLoS ONE, 10, e0127502. https://doi.org/10.1371/journal.pone.0127502. 
Lazzarotti, F., Dalfovo, M. S., \& Hoffmann, V. E. (2011). A bibliometric study of innovation based on schumpeter. Journal of Technology Management Innovation, 6, 121-135. https://doi.org/10.4067/ S0718-27242011000400010.

Lopes, A. P. V. B. V., \& De Carvalho, M. M. (2012). The evolution of the literature on innovation in cooperative relationships: A bibliometric study for the last two decades. Gestao E Producao, 19, 203-217.

Manjarrez, C. C. A., Pico, J. A. C., \& Díaz, P. A. (2016). Industry interactions in innovation systems: A bibliometric study. Latin American Business Review, 17, 207-222. https://doi.org/10.1080/10978 526.2016.1209036.

Mongeon, P., \& Paul-Hus, A. (2016). The journal coverage of web of science and scopus: A comparative analysis. Scientometrics, 106, 213-228. https://doi.org/10.1007/s11192-015-1765-5.

Morrison, H., Salhab, J., Calve-Genest, A., \& Horava, T. (2015). Open access article processing charges: DOAJ survey May 2014. Publications. https://doi.org/10.3390/publications3010001.

Muhuri, P. K., Shukla, A. K., \& Abraham, A. (2019). Industry 4.0: A bibliometric analysis and detailed overview. Engineering Applications of Artificial Intelligence, 78, 218-235. https://doi. org/10.1016/j.engappai.2018.11.007.

Padilla-Ospina, A. M., Medina-Vásquez, J. E., \& Rivera-Godoy, J. A. (2018). Financing innovation: A bibliometric analysis of the field. Journal of Business and Finance Librarianship, 23, 63-102. https ://doi.org/10.1080/08963568.2018.1448678.

Perez, C. (1983). Structural change and assimilation of new technologies in the economic and social systems. Futures, 15, 357-375. https://doi.org/10.1016/0016-3287(83)90050-2.

Phillips, W., Lee, H., Ghobadian, A., O’Regan, N., \& James, P. (2015). Social innovation and social entrepreneurship: A systematic review. Group and Organization Management, 40, 428-461. https:// doi.org/10.1177/1059601114560063.

Przychodzen, W., Przychodzen, J., \& Lerner, D. A. (2016). Critical factors for transforming creativity into sustainability. Journal of Cleaner Production, 135, 1514-1523. https://doi.org/10.1016/j.jclep ro.2016.04.102.

Research Gate. (2014). Questions. Retrieved from: https://goo.g1/VqqFkM. Accessed 22 Aug 2019.

Rosenbusch, N., Brinckmann, J., \& Bausch, A. (2011). Is innovation always beneficial? A meta-analysis of the relationship between innovation and performance in SMEs. Journal of Business Venturing, 26, 441-457. https://doi.org/10.1016/j.jbusvent.2009.12.002.

SCImago. (2018). SCImago journal ranking. Retrieved from: https://www.scimagojr.com/. Accessed 22 Aug 2019.

Scopus. (2018). Search. Retrieved from: https://www.scopus.com/. Accessed 22 Aug 2019.

Shamseer, L., Moher, D., Maduekwe, O., Turner, L., Barbour, V., Burch, R., et al. (2017). Potential predatory and legitimate biomedical journals: can you tell the difference? A cross-sectional comparison. BMC Medicine, 15, 28. https://doi.org/10.1186/s12916-017-0785-9.

Silveira, F. F., \& Zilber, S. N. (2017). Is social innovation about innovation? A bibliometric study identifying the main authors, citations and co-citations over 20 years. The International Journal of Entrepreneurship and Innovation Management, 21, 459-484.

Stilgoe, J., Owen, R., \& Macnaghten, P. (2013). Developing a framework for responsible innovation. Research Policy, 42, 1568-1580. https://doi.org/10.1016/j.respol.2013.05.008.

Sutz, J. (2000). The university-industry-government relations in Latin America. Research Policy, 29, 279-290. https://doi.org/10.1016/S0048-7333(99)00066-9.

Tardy, C. (2004). The role of English in scientific communication: Lingua franca or Tyrannosaurus rex? Journal of English for Academic Purposes, 3, 247-269. https://doi.org/10.1016/j.jeap.2003.10.001.

The World Bank. (2018). World development indicators. Retrieved from: http://bit.ly/2Zb91MP.

United Nations. (2018). Goal 9- sBuild resilient infrastructure, promote inclusive and sustainable industrialization and foster innovation [WWW document]. United Nations. https://sustainabledevelopment.un. org/sdg9. Accessed 22 Aug 2019.

van Eck, N. J., \& Waltman, L. (2010). Software survey: VOSviewer, a computer program for bibliometric mapping. Scientometrics, 84, 523-538. https://doi.org/10.1007/s11192-009-0146-3.

Wuchty, S., Jones, B. F., \& Uzzi, B. (2007). The increasing dominance of teams in production of knowledge. Science, 316, 1036-1039. https://doi.org/10.1126/science.1136099.

Zawislak, P. A., \& Dalmarco, G. (2011). The silent run: New issues and outcomes for University-industry relations in Brazil. Journal of Technology Management Innovation, 6, 66-82. https://doi.org/10.4067/ S0718-27242011000200005.

Zupic, I., \& Čater, T. (2015). Bibliometrics methods in management and organization. Organizational Research Methods, 18, 429-472. 